\title{
Analysis of Cold Chain Logistics in the Implementation of Rural Revitalization Strategy in Guangdong Province
}

\author{
Wang Shenxiang, Wei Chengyan \\ Guangzhou Industrial and Commercial College, Guangzhou, Guangdong 510850, China
}

Keywords: Cold Chain Logistics; Rural Revitalization Strategy; Implementation

\begin{abstract}
The focus of the rural revitalization strategy in Guangdong province is to develop "one village, one product, one town and one industry" to promote the integration and development of the first, second and third industries. The construction of the cold chain logistics system is an important part of the rural revitalization strategy. The cold chain logistics can improve the economic and social benefits of distinctive agricultural products in Guangdong province. The construction of the rural revitalization strategy should be implemented from the aspects of agricultural product resources, cold chain resource platform, standard system, policy construction, and personnel training mechanism etc.
\end{abstract}

\section{Introduction}

In president Xi Jinping's report at the 19th National Congress of the Communist Party of China, the strategy of rural revitalization was first proposed and it was listed as one of the seven strategies for building a well-off society in an all-round way. The implementation of the rural revitalization strategy is a major strategic deployment in China. The rural development has been raised to an unprecedented height. The circulation system of the agricultural product, especially the construction of the cold chain logistics system, is one of the important contents of the rural revitalization strategy. The opinions on implementing the rural revitalization strategy pointed out that the key issues in the sales of agricultural products should be addressed. The post-production grading, packaging and marketing of agricultural products should be strengthened, and the cold chain warehousing and logistics system of modern agricultural products should be constructed.

In recent years, China's cold chain logistics has developed rapidly. In 2017, China's agricultural cold chain logistics totaled 4 trillion yuan, the market size of the cold chain logistics was 470 billion yuan, the cold storage capacity exceeded 100 million $\mathrm{m} 3$, and the e-commerce scale of the fresh agricultural products also exceeded 139.1 billion yuan. However, the construction of the cold chain system is not perfect, and the short board phenomenon is serious, resulting in a high loss rate of perishable agricultural products. Compared with $95 \%$ of the cold chain circulation rate in developed countries, the comprehensive circulation rate of China's cold chain logistics is only $19 \%$ and the year lost for the fruit and vegetable products alone exceeded 100 billion yuan.

\section{Rural Revitalization Strategy and Current Situation of Agricultural Products Circulation in Guangdong Province}

It was pointed out in the work conference for rural revitalization in Guangdong province that the power of the whole province should be used to implement the "rural revitalization strategy", develop "one village, one product, one town and one industry", promote the integration of the development of the first, second and third industry, and take the road to focus on improving the quality of agricultural products. The implementation opinions on promoting the rural revitalization strategy were introduced, and the rural revitalization strategy was fully implemented and nearly 100 billion yuan was arranged to support the implementation of the rural revitalization strategy in 2018.

The total annual output of fruits, vegetables, meat and aquatic products in Guangdong province reached 64.21 million tons, and the cold chain circulation rate was around $20 \%, 30 \%$ and $35 \%$ respectively. The cold chain logistics volume of the self-produced agricultural product alone in the 
whole province reached 15 million tons. The cold chain logistics market is larger in terms of the service object of the cold chain logistics such as food and ingredients, pharmaceuticals, quick frozen products and flowers etc. Guangdong province is one of the most prosperous provinces with the most developed trade in China. The resident population ranks first in the country. The demand for agricultural products, the inter-provincial circulation of agricultural products and the trade volume of agricultural products are very large, which also stimulates the development of the cold chain logistics.

The cold chain logistics system, which is not compatible with the scale of agricultural products in the whole province, restricts the circulation of agricultural products. In recent years, there have been news of the slow sales of various agricultural products such as litchi, pineapple, taro, wax gourd, raw fish, native chicken, and young pigeons etc. in Guangdong, and the economic losses are huge.

\section{Cold Chain Logistics Escorts Agricultural Products and Helps Rural Revitalization}

Cold chain logistics refers to an interrelated process to control the temperature of perishable products to ensure the quality of perishable products and reduce losses during the entire process from production to consumption.

The loss ratio of fruits and vegetables in developed countries in Europe and America does not exceed 5\%. China's fruit and vegetable products have lost more than $30 \%$ due to the lack of cold chain logistics or the abnormal cold chain logistics. If the cold chain logistics system is established and perfected and the loss of fruits and vegetables is reduced to the level of developed countries, China can save 100 million mu, a unit of area ( $=0.0667$ hectares) of cultivated land each year. In Guangdong province alone, if better cold chain logistics is used, and the loss ratio of fruit and vegetable, meat products and aquatic products is decreased from $30 \%$ to 5\%, more than 15.6 million tons of agricultural products will be saved.

\section{The Benefits of Cold Chain Logistics in Implementation of Rural Revitalization Strategy in Guangdong Province}

It was pointed in the implementation opinion of rural strategy in Guangdong province that the cold chain logistics system of the modern agricultural product should be constructed mainly and the modernization of rural circulation should be accelerated, thus ensuring the completion of the rural revitalization strategy.

\subsection{Enhancing Economic Benefits of Agricultural Products in Guangdong Province}

(1) The cold chain logistics reduces the rot of agricultural products, controls the temperature of perishable agricultural products in a suitable range, and inhibits the respiration action and biological enzyme action of the agricultural products as well as the growth and reproduction of microorganisms. Cold chain logistics can avoid the damage of the physical structure of the agricultural products and the disease caused by the product corruption, thus to ensure that agricultural products reach the consumption link in the best condition.

(2) The cold chain logistics can guarantee the quality and value of the perishable agricultural products to the maximum. The cold chain logistics can prevent the agricultural products from being withering, brown stem, skin wrinkles and excessive shrinkage, and maintain good quality and value. The price for the product using the cold chain logistics will be 1-2 times higher than that for the product which doesn't use cold chain logistics.

(3) Extend the shelf life of the product through temperature control, avoid the phenomenon that the product "cannot be stored, can't be shipped out", and "local produce-local market, season produce-season market", and avoid the phenomenon that "the farmers will be hurt if the vegetables are cheap, while buyers will be hurt if the vegetable are expensive”. The enthusiasm of producers of agricultural products should be improved and their salary should be created.

(4) Through pre-cooling and fresh-keeping treatment, the added value of the products can be 
added. The post-production processing capacity of China's agricultural products is about 25\%, while this capacity in developed countries is more than $70 \%$. The added value of agricultural products can be increased by more than $50 \%$ if they are deeply processed.

(5) The cold chain logistics can help the strategy of "one village, one product, one town and one industry" in Guangdong province and increase the brand and reputation of the distinctive agricultural products in Guangdong province. The cold chain logistics system of bulk-farm products and special high-quality agricultural products is constructed to ensure the quality and landmark brand of special high-quality agricultural products.

\subsection{Increasing Social Benefits of Agricultural Products in Guangdong Province}

(1) The distinctive agricultural products in Guangdong province were led out of the place of origin to decrease the occurrence of slow sales. Establish a complete process of the distinctive agricultural products from the field to the table, solve the problem of unbalance between supply and demand between the production area and the consumption area, and give play to the market advantage of local distinctive agriculture.

(2) The cold chain logistics can provide a large number of rural employment opportunities. According to the scale of 64.21 million tons of fruits, vegetables, meat and aquatic products in Guangdong province, 24 million farmers can increase their income and the employment of 1.12 million people can be solved.

(3) The cold chain logistics can alleviate the pressure of land resources. The per capita cultivated land in Guangdong province is $0.39 \mathrm{mu}$, a unit of area (=0.0667 hectares), which is far lower than the national per capita cultivated land of $1.39 \mathrm{mu}$. The use of standardized cold chain logistics operations will save 61.92 million tons of food, 2.195 million tons of fruit, and 253.629 million tons of vegetables, equivalent to 29 million hectares of arable land.

\section{Construction of Cold Chain Logistics in Implementation of Rural Revitalization Strategy in Guangdong Province}

In regards to the construction of the cold chain logistics system in the implementation of the rural revitalization strategy in Guangdong province, various factors of agricultural product circulation in the rural revitalization in Guangdong province should be analyzed, the quality of perishable agricultural products in Guangdong province should be improved and the resources should be saved to increase income for farmers, and ensure the implementation of rural revitalization strategy.

(1) Establish a database of large-scale agricultural products and distinctive agricultural products in Guangdong province, and prepare the preliminary basis for the strategy of "one village, one product, one town and one industry" in Guangdong province.

(2) Analyze the characteristics of distinctive agricultural products in the resource pool of "one village, one product, one town and one industry", and design suitable cold chain logistics solutions for perishable agricultural products specifically to ensure the quality of agricultural products, and establish the brand of the distinctive agricultural products.

(3) Strengthen the cooperation between the government, associations and universities to analyze the cold chain logistics conditions in Guangdong province and establish the cold storage, the refrigerated truck and cold storage and processing and other resource platforms in Guangdong province. The circulation conditions should be provided for perishable agricultural products to "go out and bring in". The standardized platform for cold chain logistics of agricultural products in Guangdong province should be established, and the industry should be served by big data and artificial intelligence.

(4) Analyze the refrigerated transportation resources of highway, railway, aviation and ocean in Guangdong province, establish a three-dimensional transportation system for sea, land and air of agricultural products, and open up the "bottleneck" that restricts the circulation of perishable agricultural products.

(5) Strengthen the standard system construction of the cold chain logistics and policy support, 
and provide data support and policy guidance for the implementation of the cold chain logistics of rural revitalization strategy in Guangdong province.

(6) Analyze the situation of agricultural employees in Guangdong province, explore the training mechanism of the cold chain logistics, and establish a training system led by universities, enterprises, industry associations and the government.

(7) Build the cold chain logistics system for agricultural products of "one village, one product, one town and one industry", incorporate the cold chain logistics into the rural revitalization strategy of Guangdong province, reduce losses in agricultural circulation, save resources, save land, provide employment, increase income of rural residents and realize the comprehensive revitalization of rural areas in Guangdong province.

\section{Conclusions}

Guangdong Province is one of the provinces with the most developed economy, the most prosperous trade and the largest population in China. In regards to the construction of the cold chain logistics system in the implementation of the rural revitalization strategy, the problem of unbalanced development of the whole province should be solved and the unbalanced distribution of the cold chain logistics resources should be solved. The resource pool of the agricultural product, the optimization of the cold chain resource platform, the cold chain logistics standard system and policy, as well as the talent training mechanism, etc should be focused to be constructed.

\section{References}

[1] Xinhua News Agency was authorized to issue. The State Council of the CPC Central Committee on the Implementation of the Rural Revitalization Strategy [Z].2018.1.2.

[2] Li Jianhua, Wang Hong. Development History of Cold Storage in Guangdong [M]. Guangzhou: Lingnan Fine Arts Publishing House, 2014.

[3] Nick Gallent, Meri Juntti, Sue Kidd, et al. Introduction to rural planning [M]. London: Routledge, 2008. 